ANUARIO MUSICAL, N. ${ }^{\circ} 65$

enero-diciembre 2010, 225-250

ISSN: 0211-3538

\title{
ELASTICITAT I REFORMULACIONS MELÒDIQUES EN LES MÚSIQUES DE TRANSMISSIÓ ORAL DE LA MEDITERRÀNIA OCCIDENTAL: LES SONADES DE FLAÜTA I TAMBOR D'EIVISSA I FORMENTERA ${ }^{1}$
}

\author{
ELASTICITY AND MELODIC REFORMULATIONS IN MUSIC BY ORAL \\ TRANSMISSION IN WESTERN MEDITERRANEAN AREA: MUSIC FOR \\ FLAÜTA AND DRUM IN EIVISSA AND FORMENTERA ISLANDS
}

Jaume Escandell i Guasch

Conservatori Superior de Música de les Illes Balears

\begin{abstract}
Resum:
L'article se centra en la música instrumental de transmissió oral a les les illes d'Eivissa i Formentera. En concret, s'expliquen dos aspectes del comportament estructural detectats en el repertori litúrgic per al conjunt de flaüta i tambor. El primer de dits aspectes consisteix en el desenvolupament d'un discurs musical a partir de la reformulació constant de dos models melòdics delimitats clarament pels graus utilitzats -en relació amb tota la gamma de sons que produeix l'instrument- i per les notes de terminació. El segon fa referència a l'elasticitat que caracteritza les peces estudiades, les quals no tenen una extensió prefixada, sinó que compten amb mecanismes basats en la repetició, un nombre variable de vegades, de segments determinats, fet que permet desenvolupar versions més esteses o més reduïdes d'una mateixa peça.
\end{abstract}

Paraules clau:

Eivissa i Formentera; flaüta i tambor; Credo i Alçar Déu; transmissió oral; estructura; elasticitat; reformulacions melòdiques.

Resumen:

El presente artículo aborda la música instrumental de transmisión oral de las islas de Eivissa y Formentera. Concretamente, se explican dos aspectos del comportamiento estructural detectados en el repertorio litúrgico para flaüta y tambor. El primero de ellos consiste en el desarrollo de un discurso musical a partir de la reformulación constante de dos modelos melódicos delimitados

1 Aquest article ha estat elaborat a partir dels resultats obtinguts en el treball d'investigació corresponent al període de recerca del programa de doctorat en Musicologia titulat Lògiques estructurals en les músiques per a flaüta $i$ tambor de les Illes Pitiüses: el Credo i l'Alçar Déu, dos exemples de sonades de missa, dirigit pel Dr. Jaume Ayats Abeyà i presentat a la Universitat Autònoma de Barcelona en juny de 2008. 
claramente por los grados utilizados -en relación con toda la gama de sonidos que produce la flaüta- y por las notas de terminación. El segundo se refiere a la elasticidad que caracteriza las piezas estudiadas. Éstas no tienen una extensión prefijada, sino que cuentan con mecanismos basados en la repetición -un número variable de veces- de segmentos determinados, lo que permite desarrollar versiones más extensas o más reducidas de una misma pieza.

Palabras clave: lódicas.

Eivissa y Formentera; flaüta y tambor; Credo y Alçar Déu; transmisión oral; estructura; elasticidad; reformulaciones me-

\begin{abstract}
:
The article focuses on instrumental music of oral transmission in the islands of Eivissa and Formentera. In particular, are explained two aspects of the structural behaviour detected in liturgical repertoire for the set of flaüta and drum. The first one of these aspects consists of the development of a musical discourse from the constant reformulation of two melodic models clearly delimited by the used degrees -in relation to all the gamma of sounds that the instrument produces- and for the ending notes. The second one refers to the elasticity that characterizes the studied pieces, which do not have a prefixed extension, but have mechanisms based on a variable times repetition of determinate segments. This fact enables more widespread or more reduced versions of the same pieces.
\end{abstract}

\title{
Key Words:
} lations.

Eivissa and Formentera; flaüta and drum; Credo and Alçar Déu; oral transmission; structure; elasticity; melodic reformu-

La flaüta utilitzada a les illes d'Eivissa i Formentera (Illes Pitiüses) és un instrument aeròfon que pertany al grup de les flautes de conducte i bisell. Es tracta d'un tipus de flabiol llarg, de secció estreta i perforació lleument cònica, que morfològicament es caracteritza per tenir tres forats d'obturació a la part inferior del tub, dos a la part anterior i un a la posterior. Els dos primers es tapen amb els dits índex i del mig, mentre que el darrer es controla amb el polze. Amb el dit petit i l'anular se subjecta l'instrument pinçant-lo pel seu extrem inferior, de manera que, juntament amb els llavis, sobre els quals es fa descansar l'embocadura, s'estableixen els dos punts de recolzament necessaris per subjectar l'instrument. A la mateixa mà esquerra amb què es fa sonar la flaüta se subjecta el tambor. Més concretament, penja del canell mitjançant una corretja curta. Es fa sonar amb l'altra mà, la més destra. Generalment la flaüta se sona amb la mà esquerra $\mathrm{i}$ el tambor es percudeix amb la dreta, tot i que també hi ha casos de sonadors esquerrans que ho fan a l'inrevés (vegeu Annex).

Les situacions socials en què intervenia el conjunt instrumental flaüta-tambor en la primera meitat del segle xx eren bàsicament tres: les vetlles, les ballades i la litúrgia religiosa.

Les vetlles consistien en trobades que tenien lloc a la nit, després de sopar, en alguna casa particular. Es tractava d'un moment de relació social important en què se solien congregar familiars i veïns, i en què els joves podien aprofitar per conversar amb les al-lotes. Moltes vegades les vetlles es feien coincidir amb feines lleugeres derivades de les tasques agràries dutes a terme durant el dia, com podien ser esclovellar ametlles o desgranar dacsa, de manera que s'aprofitava la mà d'obra potencial dels assistents per fer la feina mentre es parlava, s'escoltava i s'estava en companyia. Aquestes reunions també anaven estretament 
lligades a diverses maneres de diversió: gairebé sempre hi eren presents les cançons, les sonades² de flaüta i tambor, i les petites ballades. Cal destriar, però, dos casos prou diferenciats amb presència de música de flaüta i tambor en les vetlles. En primer lloc, les vetlles espontànies en les quals hi podia haver algú que sabés sonar els instruments i executés unes quantes sonades per ajudar a animar la reunió. El segon cas seria el de les vetllades preparades i pactades, en què s'ajuntaven uns quants sonadors ${ }^{3}$ per a una feta de gaites o sessió en el transcurs de la qual anaven interpretant diferents sonades a fi d'aprendre, si era possible, nou repertori o altres variants d'una mateixa peça.

La segona de les situacions en què hi havia presència de música d'aquests instruments eren les ballades, que podien tenir lloc en el transcurs de les mateixes vetlles o bé en ocasions preparades exclusivament per ballar. El primer dels casos respon a petites ballades sorgides de manera gairebé espontània, amb un nombre més aviat reduït de participants $i$, en conseqüència, d'una durada no gaire llarga. En canvi, en el segon cas, es tractava de dates assenyalades en què cada any era costum fer una ballada en un entorn determinat: és el cas de les ballades a pous i fonts que se celebraven a Eivissa durant l'estiu, o les que tenien lloc els dies de les festes patronals de cada poble. Es caracteritzaven per una alta participació, de manera que es podien perllongar unes quantes hores. Però tan si eren espontànies com preparades, en qualsevol ballada era imprescindible la presència del sonador, ja que el tambor és el que marca la base rítmica necessària per al ball.

Finalment, la flaüta i el tambor també intervenien en l'àmbit litúrgic. En aquest sentit, la tasca del sonador consistia en fer les sonades corresponents durant la missa dels dies més assenyalats: principalment, les festes patronals de cada poble. Aquesta labor d'interpretar les sonades en el moment corresponent de la litúrgia, alguns sonadors l'anomenen servir sa missa.

En conseqüència, el repertori musical per a flaüta i tambor també es pot dividir en tres blocs: les gaites, les sonades per ballar, i les sonades de missa. Aquestes tres categories les delimiten actualment els propis sonadors, i coincideixen respectivament amb les situacions socials que acabem d'explicar: les vetlles -actualment, tots aquells moment en què se sona sense la finalitat d'acompanyar el ball o servir la missa-, les ballades i la celebració de la litúrgia.

A nivell físic i acústic, les flaütes d'Eivissa i Formentera es caracteritzen, principalment, per la manca de regularitat en les mides i, en conseqüència, per la falta d'un comportament sonor estandaritzat. Aquest fet és consequiència d'usar unes tècniques constructives que mai s'han ajustat al rigor d'uns paràmetres numèrics exactes, sinó que sempre han seguit proporcions aproximades. Així, si s'observa una variable física com és la longitud de l'instrument, se'n poden trobar de llargàries que oscil·len entre els 40 i 50 centímetres, fet que repercuteix directament en el to d'afinació. A major longitud del tub, menor és la freqüència del so fonamental de l'instrument, de manera que les més llargues tenen un so més greu que les més curtes. Una variabilitat semblant també s'observa en les proporcions entre les distàncies que guarden el tambor

2 Sonada (plural sonades) es fa servir a Eivissa i Formentera com a sinònim de peça o execució musical instrumental.

3 Sonador (plural sonadors) és el terme usat a les Pitiüses per designar el músic que toca el conjunt format per la flaüta i 
entre sí els forats d'obturació, l'embocadura i el final del tub. En aquest cas, la consequiència sonora és una relació intervàl-lica entre els diferents graus del mode o gamma de sons produït que serà diferent d'un instrument a un altre. S'està parlant, per tant, de dues variables: la nota fonamental de l'instrument, i el tipus de mode o d'intervàl-lica que se'n deriva.

Però tot i la variabilitat esmentada, si es pren la nota Sol com a model de fonamental i es transporten les intervàl-liques generades per diferents flaütes a partir d'aquest so, s'observen algunes característiques que es repeteixen amb una certa freqüència en aquests instruments. Ho podem veure a la Figura 1.

El primer que s'ha de tenir molt present és que la flaüta no és un instrument que sonorament s'ajusti a un sistema de temperament igual. Des del primer harmònic de la fonamental més greu s'organitza un mode de Sol que sovint té el III grau rebaixat, de manera que origina un interval de tercera mitjana o "neutra" amb el I. O sigui, pràcticament en una posició intermèdia entre el Si bemoll i el Si natural. Aquesta tercera encara se sol veure més rebaixada en el III', que ja apareix clarament dins de l'espai de $\mathbf{S i}$ bemoll. Cosa semblant succeeix amb el v': també és bemoll, mentre que en l'octava inferior és natural. En canvi, els graus IV, VII i, en menor mesura, I' solen aparèixer apujats.

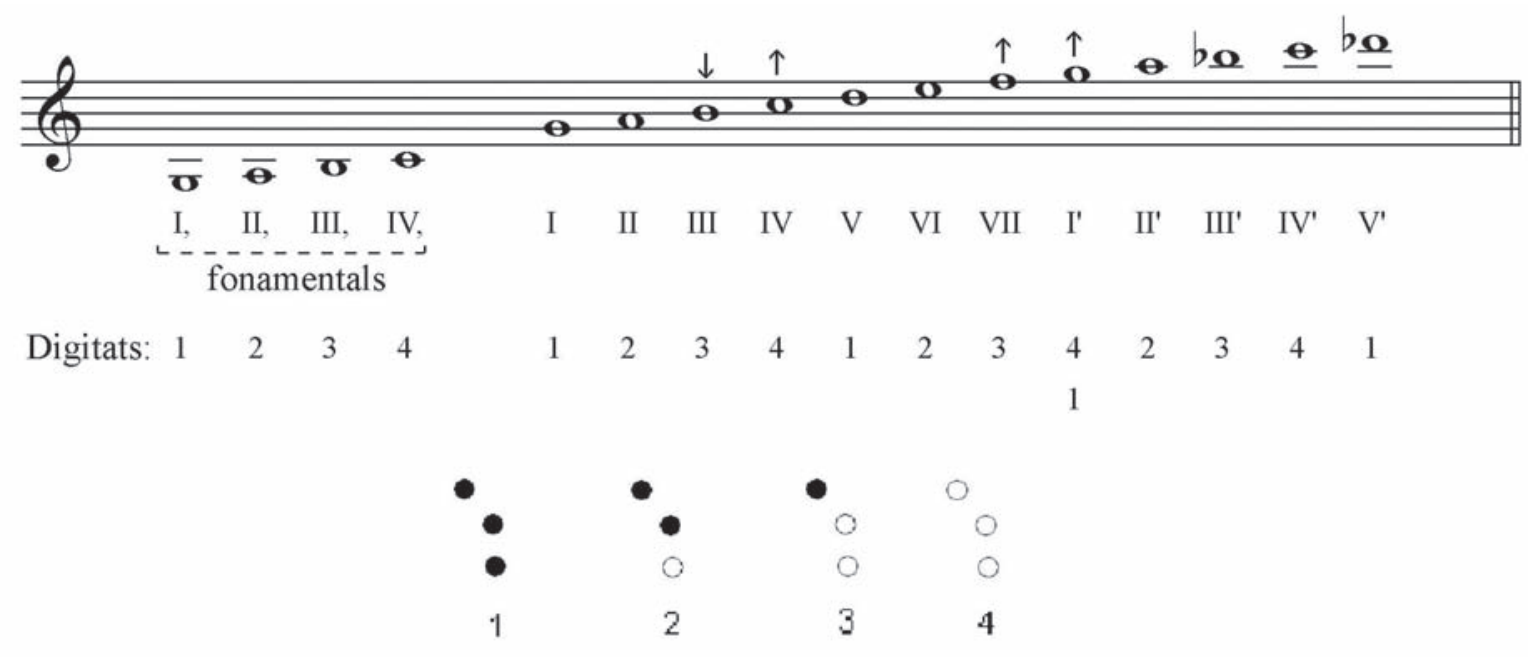

(Negre =forat tapat; blanc-forat obert)

Figura 1. Model d'afinació i digitacions.

La variabilitat entre diferents instruments, tant pel que fa al so fonamental com en el mode que generen, planteja el següent problema a l'hora d'analitzar el repertori: les alçades de les notes de cada sonada i la relació intervàl-lica entre elles no és fixa ni té valor absolut, sinó que són conseqüència d'aplicar una seqüència de digitats sobre un instrument amb unes característiques sonores concretes. Així, si un sonador executa una mateixa sonada amb dues flaütes distintes, aplicarà la mateixa 
sequiència de posicions digitals, però si les característiques sonores de la segona flaüta són diferents de la primera, la disposició dels intervals que en resultarà serà notablement diferent en els dos casos.

Per tant, si es parteix del fet que la base d'una sonada és la digitació, el que es proposa aquí és realitzar les notacions tenint en compte els graus utilitzats. Així, es mantindrà la notació sobre pentagrama, per a la qual s'emprarà el mateix àmbit exposat en el model anterior, tot i que sense afegir cap alteració ni indicació suplementària d'altura de les notes. D'aquesta manera, les notacions que segueixen s'hauran d'entendre com una simple representació dels graus (els mateixos que tenen assignats en el model de la Figura 1), tot i que s'ha de tenir en compte que, a efectes sonors, entre els graus pot haver-hi relacions intervàl-liques diferents depenent de cada instrument.

\section{METODOLOGIA ANALÍTICA}

El procés metodològic que s'ha seguit ha tingut per objectiu establir un model d'estructura que expliqués satisfactòriament les lògiques que els sonadors despleguen a l'hora d'interpretar les dues sonades escollides. Per a dur-ho a terme, a partir de les dades recollides al llarg del treball de camp s'ha desenvolupat una anàlisi que ha posat en relació els aspectes socials i els aspectes musicals. En tots dos casos cal remarcar que s'ha intentat reflectir al màxim el punt de vista dels propis actors en cada situació i cada procés analitzat; és a dir, que la visió èmica cobra un pes destacat en la recerca. En aquesta relació s'han tingut en compte diversos models de recerca etnomusicològica que podríem sintetitzar en la proposta analítica de Josep Martí .

El treball de camp s'ha realitzat a partir d'entrevistes a un petit nombre de sonadors molt destacats: tres sonadors de flaüta i tambor reconeguts socialment dins el seu col·lectiu. Dos d'ells, Toni Manonelles Bolle (*1966) -l'interlocutor principal- i Joan Escandell Marí "Taronges" (*1974), estan en actiu actualment, mentre que el tercer, Pep Bonet Tur "Mossènyers" (*1920), mestre dels dos anteriors i un dels sonadors de referència per a les generacions actuals, ja fa uns anys que no sona degut a la seua avançada edat. A fi de confeccionar i de validar el model estructural que es proposa, també s'han fet servir enregistraments d'altres dos sonadors: Toni Planells Costa "Petit" (*1936; †2003) i Toni Escandell Escandell "Parrí" (*1908; †1987).

Per realitzar l'anàlisi formal de la música, s'ha treballat amb diferents versions de dues sonades que s'interpreten durant la litúrgia de les festivitats més importants: la sonada del Credo i la d'Alçar Déu. A l'hora d'abordar-les s'ha partit del plantejament estructuralista de començar per clarificar les lògiques des de la unitat musical més gran fins arribar, per criteris de segmentació èmica i comparativa, finalment, als elements més petits. Els fonaments metodològics han estat els processos analítics seguits

4 MARTí, Josep: Más allá del arte, la música como generadora de realidades sociales. Sant Cugat del Vallès, Deriva Editorial, 2000, pp. 55-77. 
per Nicolas Ruwet ${ }^{5}$ i Simha Arom ${ }^{6}$, tot i que enriquits amb les aportacions fetes per Bernard LortatJacob $^{7}$ i Giovanni Giuriati ${ }^{8}$ en el camp de la improvisació en les músiques de transmissió oral. Així, les sonades s'han analitzat seguint tres nivells. En el primer s'ha modelitzat el mecanisme general de la peça sencera, des de que comença fins que acaba. En el segon nivell se n'ha efectuat una divisió en diferents parts, seguint sempre la segmentació èmica que n'efectua l'interlocutor principal. Finalment, en el tercer nivell s'ha explicat el funcionament intern de cadascun d'aquests segments a partir de l'anàlisi formal i comparativa.

\section{SONADA DEL CREDO}

La sonada del Credo forma part del grup de les sonades de missa, segons la terminologia èmica dels propis sonadors. A més, és una de les cinc sonades que tenen una ubicació específica dins la litúrgia. La seua interpretació solia anar estretament lligada al moment en què es resava l'oració que li dóna nom: el Credo. A l'actualitat, però, està perdent progressivament la ubicació que devia tenir més antigament -se sonava just en el mateix moment que es resava- fins al punt que avui dia alguns dels sonadors més joves no tenen del tot clara la seua ubicació dins la missa, i l'acaben incorporant en altres moments, especialment durant la comunió. La major part dels sonadors, però, l'interpreten immediatament després d'acabar de resar el Credo.

\section{Primer nivell. Organització del conjunt de la sonada}

Cal partir del fet que totes les peces que conformen el repertori per a flaüta i tambor s'articulen a partir d'un principi cíclic que s'estableix entre dos punts de la seqüència melòdica. El Credo no n'és cap excepció, sinó que també s'avé amb aquesta mecànica. Aquest comportament cíclic es troba a dos nivells: en la macroestructura, és a dir, quan es contempla tota la peça d'una manera global, des de que comença fins que acaba. I també en el nivell microestructural: en dividir la sonada en segments més petits, alguns d'ells també obeeixen al mateix comportament. Per tant, per evitar confusions, la paraula cicle s'emprarà només en el primer dels casos, quan es faci referència a la macroestructura.

5 Ruwet, Nicolas: "Méthodes d'analyse en musicologie", a Revue Belge de Musicologie, núm. 20 (1966), pp. 65-90.

6 Arom, Simha: "Modélisation et modèles dans les musiques de tradition orale", a Analyse Musicale, núm. 67 (1991), pp. 62-78, traducció de Jaume Ayats a Cruces, Francisco (ed.) : Las culturas musicales. Lecturas de etnomusicología. Madrid, Editorial Trotta, 2001, pp. 203-232.

7 LORTAT-JACOB, Bernard : “Improvisation : le modèle et ses réalisations”, a LORTAT-JACOB, Bernard (ed.): L'improvisation dans les musiques de tradition orale. París, SELAF, 1987, pp. 45-49.

8 GIURIATI, Giovanni: "Percorsi improvvisativi nella musica strumentale dell'Italia centromeridionale", a GiURIATI, Giovanni i altres: Forme e comportamenti della musica folklorica italiana. Milano, Edizioni Unicopli, 1985, pp. 15-43. 
Aquest terme no el trobem utilitzat pels sonadors, de manera que l'introduïm aquí com a terminologia ètica. El definirem com el segment de la sonada delimitat per dos punts A i B, de manera que en arribar a B s'enllaça directament amb A i des d'aquest es torna a efectuar el recorregut fins a B un nombre variable de vegades.
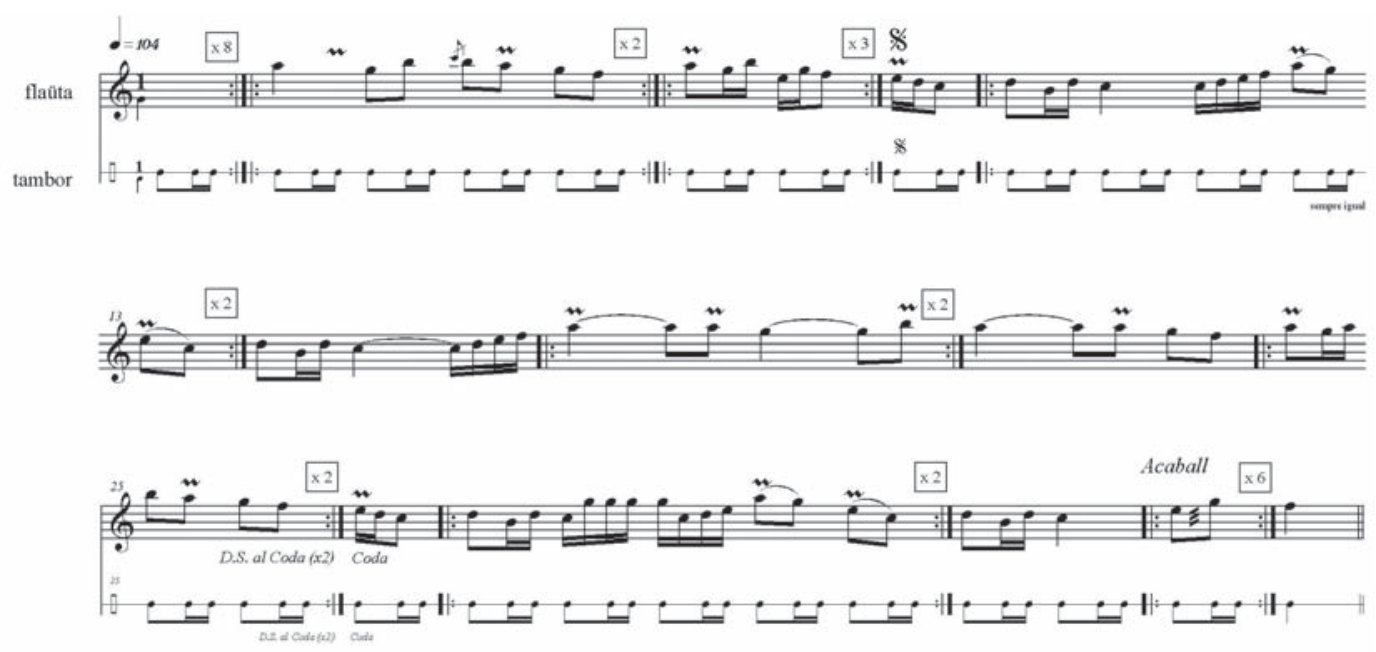

Figura 2. Sonada del Credo. Toni Manonelles9.
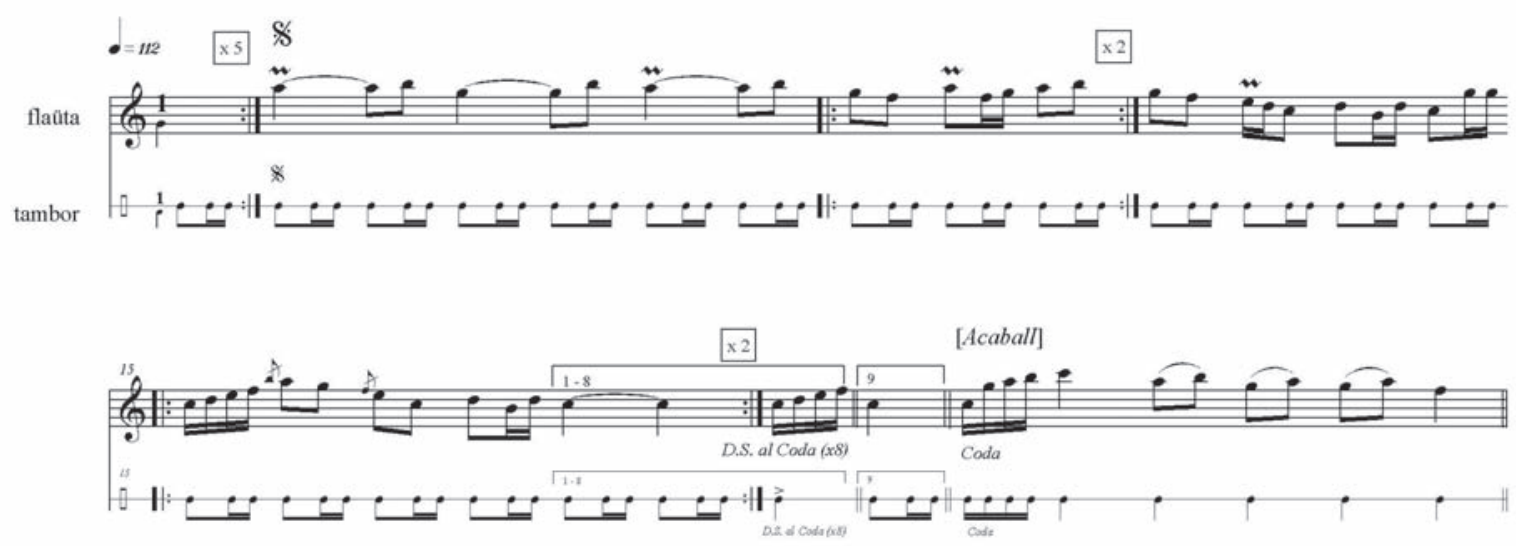

Figura 3. Sonada del Credo [Kyries]. Toni "Petit"10.

9 Totes les notacions de sonades interpretades per Toni Manonelles Bolle que apareixen en el present article han estat realitzades a partir dels enregistraments efectuats a aquest sonador durant el treball de camp l'any 2007, material inèdit, fons particular. particular.

10 Notació realitzada a partir d'un enregistrament efectuat a Toni Planells Costa "Petit" l'any 1982, material inèdit, fons 
En les Figures 2 i 3 s'ofereix la notació de dues versions d'aquesta sonada interpretades per sonadors distints. En la Figura 3, el sonador l'anomena Kyries en comptes de Credo, tot i que la correspondència dels seus elements permet afirmar que ens trobem davant una mateixa sonada. Es tracta doncs, d'un fet que demostra aquesta progressiva confusió abans esmentada pel que fa a la seua ubicació dins la missa. Les notacions mostren les sonades completes, totalment desplegades des de l'inici fins al final. El cicle correspon al segment acotat per les indicacions de repetició Dal Segno.

La sonada del Credo consta de dos elements ben diferenciats. D'una banda, l'obstinat rítmic, que inicialment es presenta tot sol en forma de petita introducció del toc de la sonada, d'extensió variable, i que després es manté al llarg de tota la interpretació. En segon lloc, la sonada pròpiament dita, com a part melòdica que constitueix el veritable corpus de la peça. Al mateix temps, dins aquesta es destrien dues parts ben clares: el cicle i l'acaball.

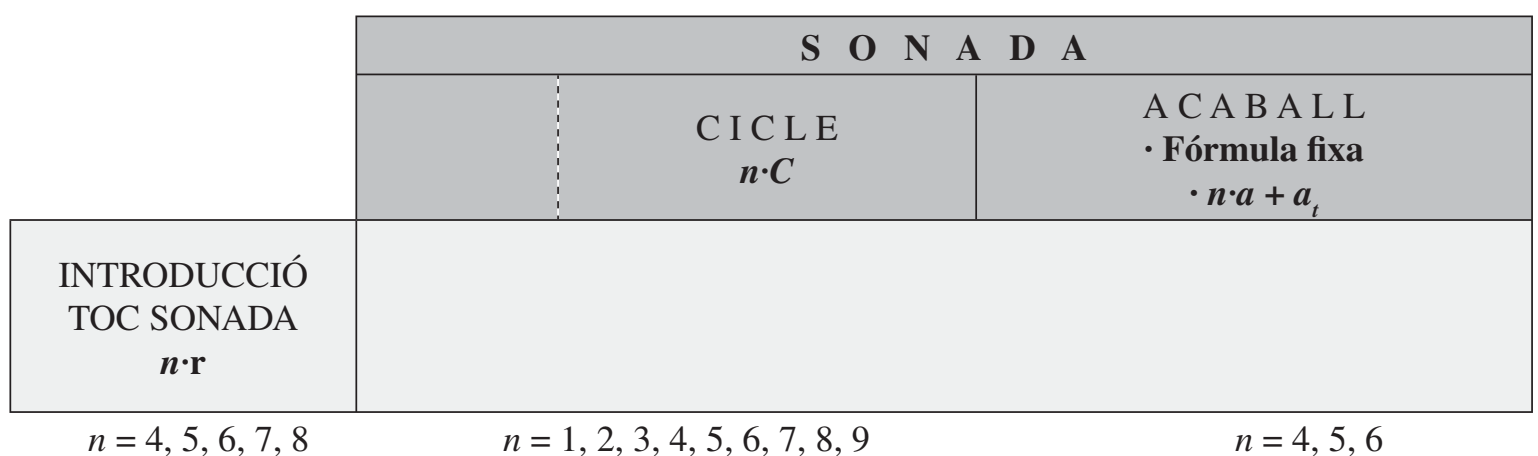

Figura 4. Esquema de funcionament del Credo.

Per tant, la sonada del Credo s'inicia sempre amb el tambor tot sol, amb el toc característic de la sonada, basat en la reiteració de la partícula rítmica (r) que presenta l'obstinat que es mantindrà durant tota la peça. La introducció no és de durada fixa, sinó que unes vegades es pot fer més llarga i d'altres més curta. Parlant en termes matemàtics, $\boldsymbol{r}$ es pot executar un nombre variable de vegades $(\boldsymbol{n})$. Al llarg de les versions analitzades, $\boldsymbol{n}$ pren el valor de 4, 5 o 8, de manera que hom es pot fer una idea dels marges de realització en què es mou aquest valor. Val a dir que mai es tracta d'un paràmetre que els sonadors comptabilitzin de manera exacta, sinó que inicien la part melòdica quan ja han assentat i assimilat bé el ritme.

La lògica de funcionament d'aquesta introducció no constitueix un fet aïllat, com es podrà veure al llarg de l'anàlisi. Per aquest motiu, serà útil introduir el concepte d'elasticitat aplicat a un segment musical, per fer referència a fragments que no sempre tenen la mateixa durada, sinó que poden créixer o minvar afegint o llevant repeticions d'una partícula breu. Aquest concepte d'elasticitat el manllevem a Giovanni Giuriati en els seus estudis de les músiques de transmissió oral del centre d'Itàlia ${ }^{11}$.

11 GIURIATI, Giovanni: "Parties fixes et "à rallonges": le saltarello di Amatrice", a LORTAT-JACOB, Bernard (ed.): L'improvisation dans les musiques de tradition orale. París, SELAF, 1987, pp. 251-253. 
A continuació de la introducció rítmica, i sobreposant-se a l'obstinat rítmic que continua, s'inicia la sonada en si. Es tracta de la part melòdica que fa la flaüta, i dins la qual s'estableix un cicle $\boldsymbol{C}$ que s'exposa un nombre variable de vegades $(\boldsymbol{n})$. $\boldsymbol{C}$ pot coincidir amb tota l'extensió de la sonada o bé quedar restringit a una porció menor com succeeix en els dos exemples presentats (Figures 2 i 3). En aquesta part de la sonada, $\boldsymbol{n}$ també pot representar diferents valors. En el conjunt de material estudiat pren els valors de 2, 3 o 9, però el testimoni dels sonadors actuals confirma que el nombre mínim és 1, mentre que més de 3 ja es considera massa. En el fons, el nombre d'exposicions del cicle depèn de la situació en què s'executi el Credo. El cas de la Figura 3, en què el cicle s'executa nou vegades, podria justificar-se de diverses maneres. D'una banda, per la brevetat del cicle en comparació amb les altres versions. Però per altra part, i cercant una argumentació més elaborada, es poden relacionar les nou execucions del cicle de la sonada que aquest sonador anomena Kyries amb les nou parts en què quedà establerta l'oració del Kyrie posterior al concili de Trento: 3 Kyrie eleison +3 Christe eleison +3 Kyrie eleison $=9$ segments ${ }^{12}$. Per tant, amb el material de què disposem, podem establir que, en la sonada del Credo, $\boldsymbol{C}$ s'executa $\boldsymbol{n}$ vegades, i generalment $\boldsymbol{n}=1,2$ o 3 . A més, cal dir que $\boldsymbol{n}$ és pràcticament sempre un nombre sencer, i seran molt rares les vegades en què no ho sigui.

Quan el cicle de la sonada ja s'ha executat les vegades desitjades o les que el moment de la litúrgia ha permès, s'insereix l'acaball per concloure la peça. Es tracta d'una petita fórmula melòdico-rítmica d'acabament que, segons les versions amb què s'ha treballat, pot respondre a dos models diferents de funcionament:

a. Fórmula fixa, pròpia de cada sonador, executada sempre igual i que pot ser aplicada, amb la mateixa funció, a altres sonades (Figura 3, pulsacions 23-28).

b. Fórmula de dimensió variable, regida pel mateix principi d'elasticitat que la introducció amb el toc del tambor, i que segueix la lògica $\boldsymbol{n} \cdot \boldsymbol{a}+\boldsymbol{a}_{\boldsymbol{t}}$, on $\boldsymbol{a}$ és una partícula melòdica que es repeteix $\boldsymbol{n}$ vegades i $\boldsymbol{a}_{\boldsymbol{t}}$ la nota final de resolució. En aquest cas, $\boldsymbol{n}=4,5$ o 6. (Figura 2, pulsacions 35-36).

Val a dir que acaball és un terme èmic, explicitat pels propis sonadors, els quals li atorguen el mateix significat que acabem d'explicar: fórmula o bocí que serveix per concloure una sonada.

A partir del segon nivell centrarem l'anàlisi només en la línia melòdica de la flaüta, ja que la part del tambor no és estructuralment significativa, doncs únicament proporciona l'obstinat rítmic constant i invariable al llarg de tota l'execució.

\section{Segon nivell. Segmentació de la SONADA}

Després d'unes primeres anàlisis de diferents versions de la sonada realitzades per nosaltres mitjançant el mètode analític estructuralista proposat per Ruwet, Nattiez i Arom, emprant la repetició com a criteri

12 Observació aportada per Jaume Ayats. 
únic i rigorós de segmentació, vam voler fer un pas més endavant i proposar al mateix interlocutor principal del treball de camp una partició de la sonada del Credo en fragments que per a ell fossin musicalment coherents. Amb aquesta intenció, partírem de la narració en què ell descrivia la manera com el seu mestre li ensenyava les sonades. Explicava com aquell segmentava les sonades en parts més petites per anar-les ensenyant progressivament i de manera sumativa. Aquestes porcions, però, no les feia aleatòriament, sinó que sempre delimitava els mateixos segments i els anomenava amb el mot genèric bocí.

Per tant, tenint en compte que l'hora de transmetre una sonada de mestre a alumne era el moment en què més fàcilment podia emergir l'estructura èmica d'una sonada, la proposta que es va fer al sonador Toni Manonelles, l'informador principal, va ser que segmentés la sonada del Credo en bocins, com si l'hagués d'ensenyar a algú altre. El procés el va realitzar en tres ocasions, separades entre si temporalment, i les delimitacions varen ser idèntiques en els tres casos. Vegeu-ho en la Figura 5.

Des de la perspectiva del propi sonador, la sonada es pot dividir en vuit bocins que encara guarden sentit musical de manera aillada. En la Figura 5, aquests s'han assenyalat amb números romans. Tots els bocins (tret del III) sofreixen un procés de repetició: en alguns casos es repeteix el bocí sencer (I, II, IV i vI), mentre que en altres casos és només una part del mateix (v i VII). El nombre entre claudàtors que figura a sobre de la barra de repetició indica el nombre total d'execucions del segment acotat entre les dobles barres de repetició. Els bocins sempre segueixen un mateix ordre que no es pot alterar, el mateix que indica la numeració romana.

La notació de la Figura 5 cal llegir-la de dalt cap avall i d'esquerra a dreta. Cada canvi de línia implica un bocí nou. Encara que alguns bocins comparteixin partícules iguals, no s'han encolumnat, ja que el sonador considera que es tracta de segments distints. Només el bocí vII s'ha alineat amb el III i el IV, ja que explícitament el propi intèrpret ha considerat que eren el mateix, tot i que ha deixat clar que no són permutables (amb una articulació de semicorxeres a vir que assenyalen l'anada a l'acaball final).

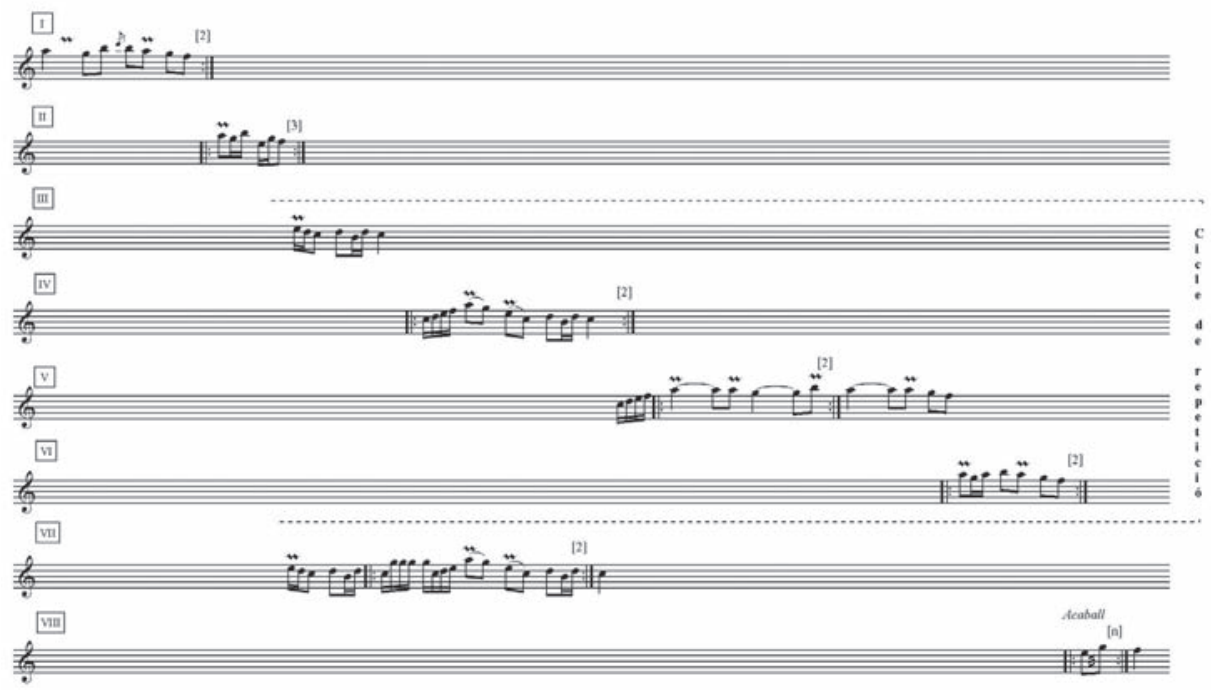

Figura 5. Segmentació èmica de la sonada del Credo. Toni Manonelles. 
Els resultats de la segmentació èmica es mostren més sòlids que els obtinguts inicialment amb el mètode analític estructuralista mencionat abans. Aquesta major coherència del que podríem anomenar "gramàtica musical" es demostra a partir dels següents fets.

El Do negra, com a figura llarga dins el discurs musical de la sonada, funciona com a clàusula final dels bocins on apareix, i per aquest motiu el bocí III queda escindit del IV -fet que no ocorria quan s'aplicava el sistema de segmentació basat en la repetició com a criteri únic i rigorós-. De la mateixa manera s'explica que el bocí vII equivalgui al III més el IV, ja que, com justificava el mateix sonador, és el mateix amb un afegitó; dit afegitó són els quatre Sols semicorxeres en què queda transformat el Do negra anterior. Així, aquest desapareix i en conseqüència també s'elimina la separació entre III i IV, donant lloc a un bocí únic: el viI. I per major coherència encara, el bocí IV també es clou amb la mateixa figura i nota. Però a més d'aquesta fórmula d'acabament, n'apareix una altra que es reitera diverses vegades, sempre en posició final d'un bocí. Es tracta del Sol-Fa corxeres, cèl-lula que tanca els bocins I, v i vi, a més del II en forma reduïda. Per tant, els set bocins que el sonador delimita només tenen les dues possibilitats de terminació esmentades.

Igualment que s'observen constants en les fórmules d'acabament, també es poden establir patrons d'inici. Els bocins III i VII comencen amb una mateixa fórmula, mentre que els iv i el v en comparteixen una altra. L'I, el II i el VI es poden considerar un tercer grup, tot i no presentar una coincidència tan gran com en els altres dos. Així doncs, l'inici del II i del vi és la mateixa figuració rítmica i només canvia l'última nota. El principi del bocí I, en canvi, és el mateix que el del II, però amb ampliació rítmica al doble.

Totes aquestes partícules apareixen només en posició d'inici o de final de bocí, segons sigui el cas, i mai es troben en altra posició. Aquest fet ja no l'arriba a explicitar el sonador, però emergeix en analitzar la seua pròpia segmentació èmica a través de procediments analítics formals-comparatius.

Per tant, cal entendre el cicle de la sonada del Credo com un seguit melòdic compartimentat en bocins, els quals estan delimitats, al mateix temps, per uns nuclis més petits que actuen d'inici i per uns altres que fan funció de clàusula. Alguns dels bocins es repeteixen totalment, mentre que en altres només es repeteix una porció del bocí. En tots els casos, però, les repeticions de les parts en qüestió són senceres, i mai fraccionàries: els bocins o parts d'ells s'executen 2 o 3 vegades, segons el cas. La conseqüència d'aquest tipus de funcionament és la partició de la peça en segments de distinta dimensió pel que fa al nombre de pulsacions, fet que probablement cridi l'atenció de l'analista format en la lògica musical més acadèmica.

\section{Tercer nivell. Organització dels bocins.}

En aquesta etapa de l'anàlisi ja no era factible una segmentació èmica dels bocins anteriors en unitats encara més petites. Cal tenir en compte que en la pràctica habitual dels sonadors les sonades s'interpreten sempre seguides, i només a l'hora d'ensenyar-les s'arriben a fragmentar en segments com els que emergiren en el segon nivell. Per tant, en aquest bloc els resultats ja s'obtenen per la via de les deduccions derivades del comparatisme formal. 
L'existència de partícules invariables tant en posició inicial com final es veu d'una manera molt més clara en la Figura 6, en la qual s'han alineat verticalment les fórmules d'inici a partir de la nota inicial, mentre que amb les de terminació s'ha fet des de la seua nota final. A més, es destrien les diferents tipologies que resulten en cada cas.

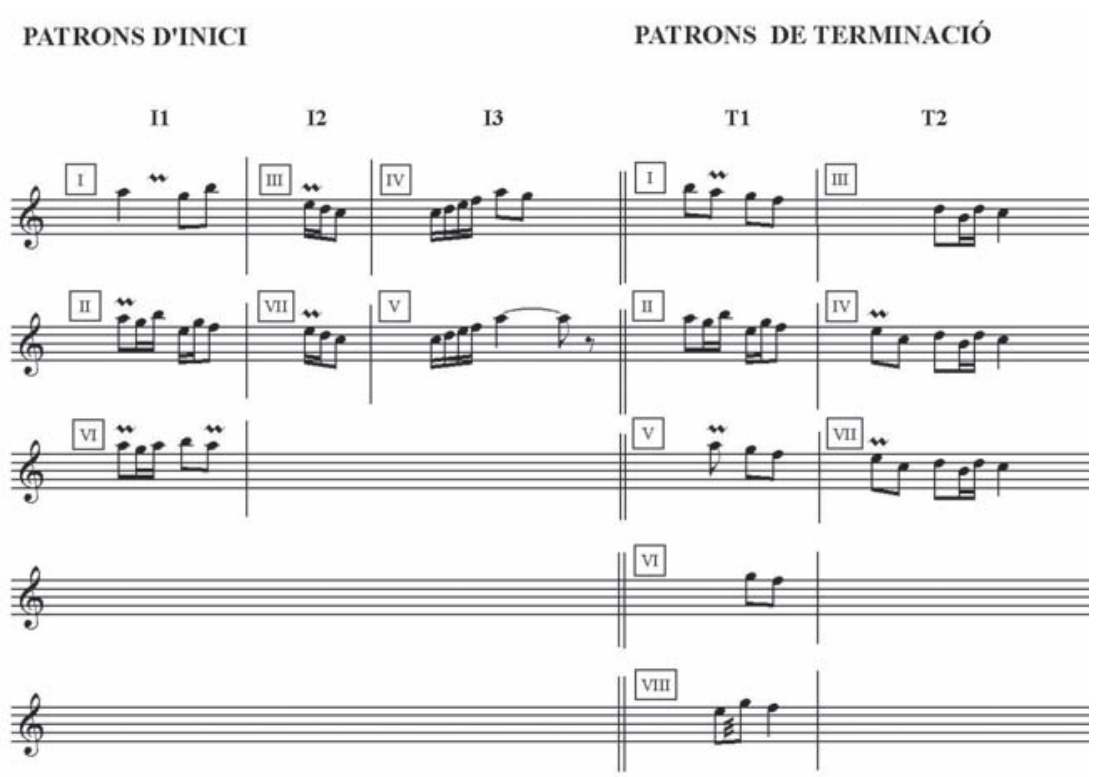

Figura 6. Patrons d'inici i de terminació dels bocins.

S'obtenen, així, tres patrons d'inici, $I 1, I 2$ i $I 3$, i dos de terminació: $T l$ i $T 2$. Pel que fa als d'inici, Il parteix sempre d'un La i és seguit sempre per un Sol i després per un Si o bé un altre La. La primera nota és sempre més llarga, mentre que les altres dues són la meitat més curtes. I2 és sempre idèntic, i consisteix en un moviment descendent per graus conjunts que parteix de Mi per arribar a Do. La proporció rítmica que guarden les notes és inversa a $I l$, ja que les dues figures breus es troben al principi i s'acaba amb la més llarga. 13 parteix de Do i va fins a Fa per graus conjunts, amb valors ràpids i iguals, per després botar a La, la qual té un valor més llarg. Quant als patrons de terminació, 1 és una conclusió sobre Fa provenint de Sol, amb un valor rítmic igual o superior a les notes precedents, mentre que $T 2$ és un repòs sobre Do amb un valor llarg, al qual s'arriba des d'un Re ornamentat amb una brodadura de tercera inferior.

L'estudi de la mecànica dels segments a partir de les seues fórmules d'inici i d'acabament condueix, encara, a una altra via d'anàlisi centrada en el comportament melòdic de cada bocí. En aquest procés s'han tingut en compte dos criteris mínims. En primer lloc, el perfil melòdic, entenent aquest com la successió rigorosa de sons que conformen el bocí, i desestimant el component rítmic. 
En segon 1loc, els graus utilitzats en cada bocí en relació als que apareixen al llarg de l'execució. En tots dos criteris cal tenir en compte que tot i expressar els sons com a notes determinades, en el fons aquestes fan referència als graus del mode corresponent que genera cada instrument segons s'explica a l'inici de l'article.

Primerament calia veure si els diferents bocins admetien una simplificació fins arribar a una forma més simple i irreductible, seguint el mateix procediment que Simha Arom va aplicar, en l'aspecte rítmic, a músiques centre africanes ${ }^{13}$. Per tant, es va proposar a l'interlocutor principal del treball de camp, Toni Manonelles, que executés cada bocí de la manera més simplificada possible. En la pràctica, però, el procés no va ser factible, ja que tampoc és habitual dins la pràctica dels sonadors ni tan sols a l'hora d'ensenyar: únicament va gosar esquematitzar el bocí I, que quedà de la següent manera:

Si s'obs̊erven els vuit bocins que conformen la sonada del Credo tenint en compte els dos criteris mencionats anteriorment -per al bocí I es pren la forma simplificada-, es destrien clarament dos grups, que aquí anomenem grup Fa i grup Do, en referència a llur nota de terminació.

Pel que fa als bocins que s'ajusten al grup Fa, les seues seqüències melòdiques són les que s'exposen a la Figura 7.

El bocí viII, per les seues dimensions i per la funció que té dins la sonada, no s'ha considerat grup Fa, sinó una terminació Fa però fora del disseny comú a aquest grup. En el bocí v, les quatre semicorxeres inicials Do-Re-Mi-Fa no s'han tingut en compte a l'hora de traçar el perfil melòdic d'aquest bocí, ja que s'han considerat com a una ornamentació amb funció d'enllaç entre els bocins IV i v. Una vegada fetes aquestes apreciacions, es pot observar com els bocins I, II, v i VI responen a un perfil melòdic força semblant, amb un inici i un acabament que sempre coincideix, mentre que a la part central apareix una àrea variable, en la qual poden aparèixer les notes $\mathbf{S i}$, La i Sol en diferent ordre.

Pel que fa als acabaments, i com a únic fet discordant, en el bocí II apareix un Mi en la posició que pertocaria aparèixer un La. El Mi, tot i ser la nota més greu, no actua com a nota de repòs; aquesta funció recau en el Fa, i el Mi actua com a auxiliar o brodadura inferior del Fa. A més, cal remarcar que el Mi i el La són dues notes equivalents pel que fa a digitació de l'instrument (vegeu Figura 1), motiu pel qual s'ha indicat el La a sobre del Mi en el perfil melòdic del bocí II.

13 Arom, Simha: op. cit., pp. 203-232. 

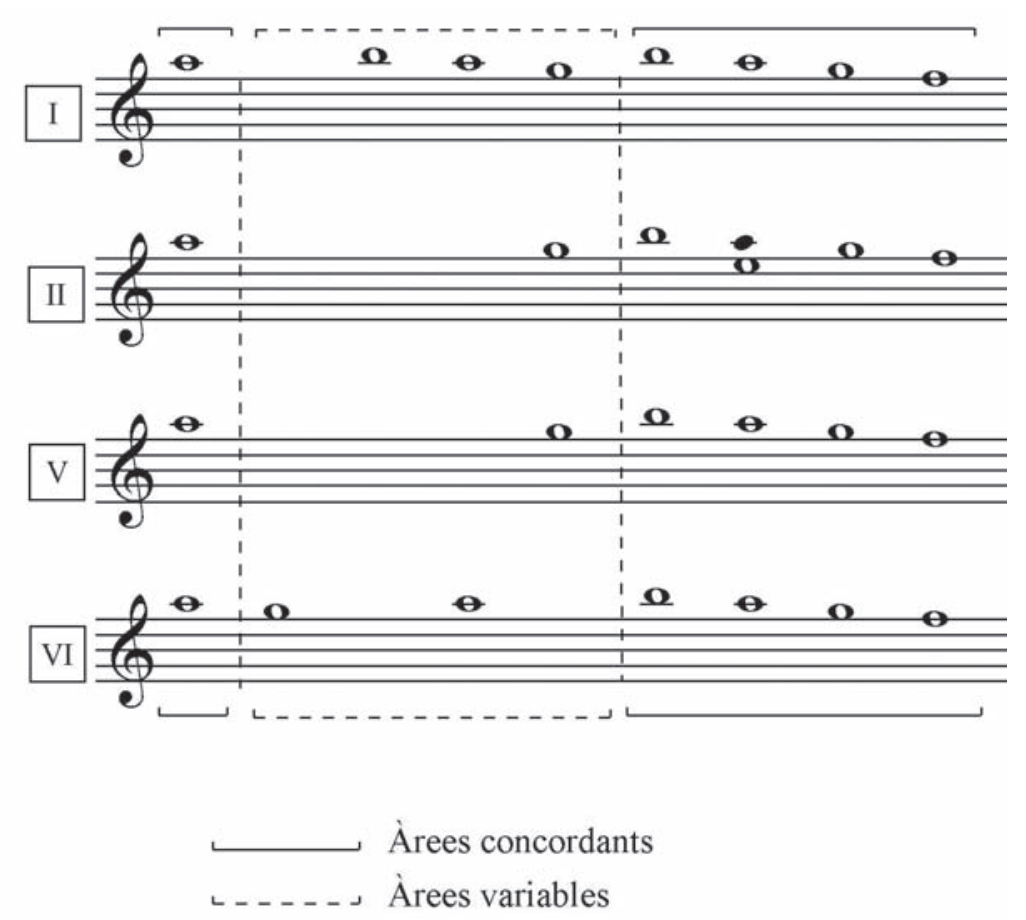

Figura 7. Perfil melòdic dels bocins corresponents al grup Fa.

A partir de tot el que s'acaba d'exposar, les característiques del grup Fa es poden resumir de la següent manera:

- Ús dels graus Si-La-Sol-Fa, amb l'aparició esporàdica del Mi com a auxiliar inferior.

- Melòdicament es pot parlar d'un inici i d'un final fixos, amb una part central variable. El començament és sempre en La, en part rítmicament forta i amb un valor llarg en relació a la resta del bocí. L'àrea variable es troba sempre a continuació d'aquest inici, i melòdicament juga amb les notes $\mathbf{S i}$, La i Sol, en diferent ordre. La part final és una línia descendent per graus conjunts des del Si fins al Fa, el qual apareix única i exclusivament en la darrera posició d'aquest final fix.

- El model melòdic resultant del grup Fa és el següent:

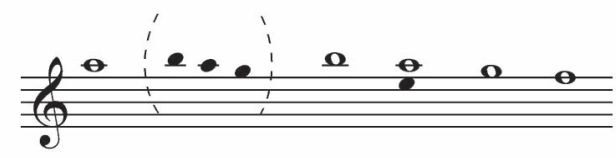

- D'aquesta manera, els bocins I, II, v i vi es poden entendre com diferents formulacions del model melòdic anterior, cadascuna de les quals ocupa un lloc determinat i no permutable dins el discurs musical 
de la sonada. Les diferències entre els quatre bocins són principalment de tipus rítmic i mètric: cap d'ells ocupa el mateix nombre de pulsacions. Així, r és l'exposició del bocí, amb 4 x 2 pulsacions de durada. El segueix II, que es pot considerar la versió estreta, amb 2 x 2 pulsacions. El bocí v en representa una versió més extensa, amb 12 pulsacions, i el bocí vi tornaria a ser una versió més estreta, amb reducció de l'inici i de la part variable (sempre en relació a I).

En segon lloc cal parlar del grup Do, al qual pertanyen els bocins III+IV i VII. Anteriorment ja s'ha explicat que des del punt de vista èmic, III+IV i vII és considerat el mateix, però amb un afegit en aquest últim que es pot considerar un embelliment. Es tracta del desplegament del Do negra del final del III en una successió de semicorxeres repetides Do-Sol-Sol-Sol al bocí viI. Tenint en compte que aquest Sol sorgeix de la mateixa digitació que la nota Do però en un altre nivell d'intensitat de buf, ens trobem davant un cas semblant al del Mi i el La del bocí II quan explicàvem el grup Fa: ambdues notes es poden considerar equivalents. A més, però, aquesta repetició de la nota Sol té una funció ben clara i explicitada pel sonador: indicar que ja s'ha sortit del cicle de repetició i que tot seguit s'inserirà l'acaball. Per tant, es pot afirmar que la repetició del Sol en semicorxeres és una marca de final inconfusible per al codi èmic d'aquest sonador. Les seqüències melòdiques estrictes de tots dos segments són les següents:

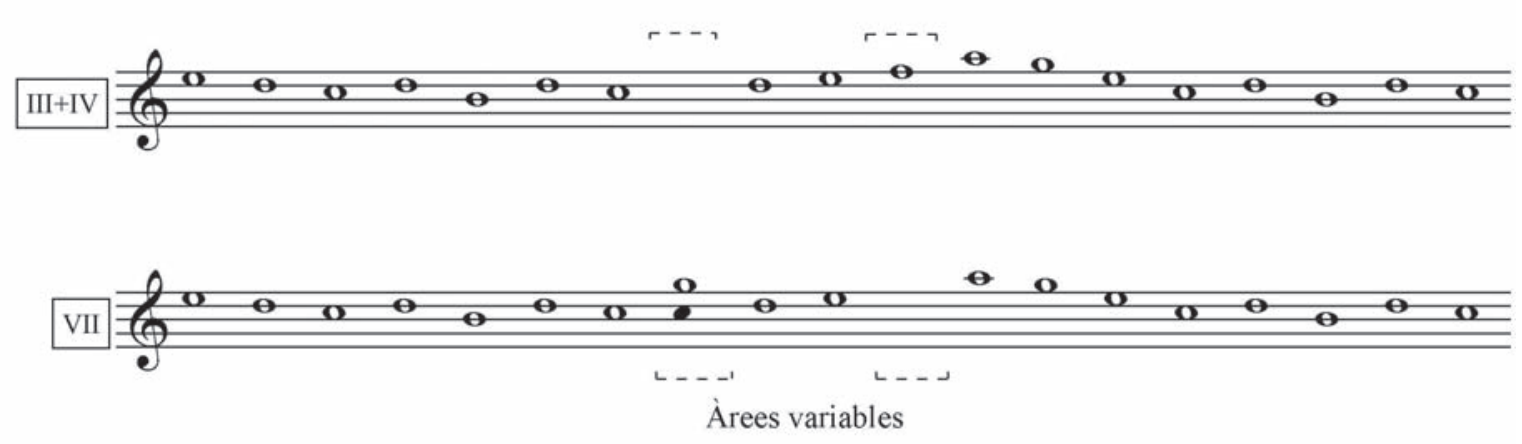

Figura 8. Perfil melòdic dels bocins corresponents al grup Do.

D'entrada es pot apreciar com els bocins del grup Do tenen un grau més alt de coincidència entre ells que no els del grup Fa. De fet, la variabilitat de nou es troba a la part central dels segments, i és deguda a la ja esmentada conversió del Do negra en la successió de semicorxeres, o sigui, només varia la marca d'entrar a la part final. És també en aquest punt on apareixen les úniques diferències rítmiques, però a nivell d'espai ocupat resulten equivalents, ja que tant III+IV com VII es desenvolupen al llarg de 13 pulsacions. Les característiques del grup Do són les següents:

- Ús dels graus La-Sol-Mi-Re-Do-Si. El Si apareix com a brodadura inferior de Do, el qual és la nota de repòs final. 
- Com succeïa en el grup Fa, la variabilitat es troba a la part central, mentre que els extrems són fixos, no presenten variació.

- El model melòdic que resulta del grup Do és el següent, tenint en compte que s'han pres com a graus principals els que ocupen la posició inicial de cada valor de corxera. D'igual manera, els embelliments i enllaços (pulsacions 3 i 4 de cada segment) s'han assenyalat entre parèntesi.

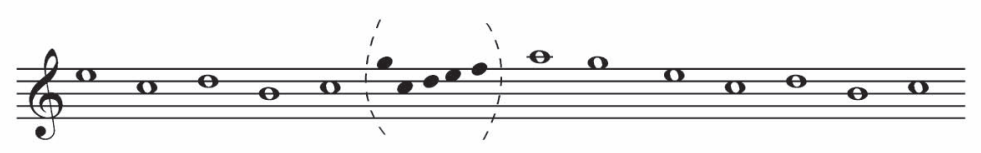

Per tant, queden ben definits els dos grups, Fa i Do, cadascun amb un perfil melòdic ben clar i amb l'ús d'uns determinats graus característics. Tot junt condiciona la delimitació de dues disposicions dels graus o modes, que al mateix temps mostren dues àrees melòdiques en relació al total de sons que conformen la sonada.

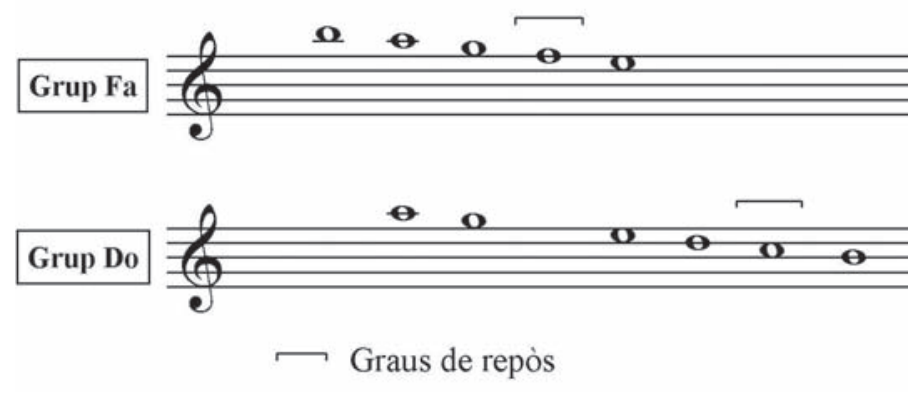

Figura 9. Sectors melòdics dels grups Fa i Do.

A partir de la distribució de la Figura 9 sobresurt un fet important: el principi de contrast que mantenen els grups Fa i Do. En el grup Fa no apareix la nota Do, que és la nota final del grup Do, i a l'inrevés; en el grup Do no apareix la nota Fa que és la nota final del grup Fa.

Només queda per explicar la forma de combinació dels grups Fa i Do al llarg de l'estructura completa de la sonada del Credo. Tenint en compte la pertinença dels vuit bocins (Figura 5) a un o altre grup melòdic, la seqüència que resulta és $\mathrm{Fa}-\mathrm{Fa}-\mathrm{Do}-\mathrm{Do}-\mathrm{Fa}-\mathrm{Fa}-\mathrm{Do}-\mathrm{fa}$. Les majúscules fan referència a un grup sencer, mentre que les minúscules, només a la terminació corresponent. S'observa, doncs, com els extrems de la sonada són grups Fa, mentre que els Do apareixen, per dir-ho d'alguna manera, en part interior. Es crea, així, una estructura contrastant entre Fa i Do que, de manera més estesa o més reduïda, també s'obté en les versions analitzades dels altres sonadors. 


\begin{tabular}{|c|c|}
\hline $\begin{array}{c}\text { Bocins del Credo } \\
\text { Toni Manonelles }\end{array}$ & Grup melòdic \\
\hline I & FA \\
\hline II & FA \\
\hline III & DO \\
\hline IV & DO \\
\hline V & FA \\
\hline VI & FA \\
\hline VII & DO \\
\hline VIII & fa \\
\hline
\end{tabular}

Recapitulant tot el procés analític realitzat des del començament, s'observa una constant que s'ha produït en tots els nivells analitzats: un procés de variabilitat inserida entre extrems fixos. Primerament hem argumentat aquesta lògica per explicar el funcionament global de l'execució del Credo. En aquell cas, els bocins I i II s'executaven una sola vegada, a l'inici, a l'igual que els VII i VIII en el cas del final. En canvi, la flexibilitat es trobava en els III-IV-V-VI, al llarg dels quals s'establia el cicle de repetició i, per tant, la possibilitat d'allargar o escurçar l'execució. És a dir, que les parts fixes es trobaven en els extrems. Aquest principi, aplicat a la morfologia dels bocins, és el que hem tornat a trobar després a nivell microestructural: hem establert tipologies fixes d'inici i de final dels bocins, mentre que en les parts internes és on apareixen les diferències entre els uns i els altres. Finalment, en l'anàlisi melòdica, aquest fet s'ha vist confirmat de nou en analitzar els models melòdics dels grups Fa i Do, en els quals la variabilitat apareix sempre en la part central, mentre que els extrems són formulacions fixes.

\section{SONADA D'ALCGR DÉU}

En la sonada del Credo queda ben il·lustrat un dels dos mecanismes que aquí volíem presentar: el desenvolupament d'un discurs melòdic a partir de diferents reformulacions, amb major o menor grau d'ornamentació, d'unes seqüències melòdiques bàsiques -els grups Fa i Do-. Centrem-nos ara en el segon dels mecanismes: l'elasticitat com a recurs habitual en les sonades de flaüta i tambor. Ja hem mencionat aquest procediment abans en el Credo, tant a nivell macroestructural -amb la possibilitat d'executar el cicle un nombre variable de vegades-, com a nivell microestructural quan hem explicat el funcionament de l'acaball. Però és en l'altra sonada estudiada, la d'Alçar Déu, on es pot observar aquest mateix mecanisme molt més ben exemplificat. 
L'Alçar Déu també forma part del grup abans esmentat de les sonades de missa que conserven una ubicació determinada durant la celebració de la litúrgia. Però a diferència del que succeeix amb el Credo, l'Alçar Déu no ofereix dubtes pel que fa a l'hora de ser sonat: es correspon amb el moment de la consagració, amb l'elevació del pa i del vi. La majoria dels sonadors que a l'actualitat interpreten aquesta sonada dins l'església la comencen en el moment en què el capellà pronuncia les paraules: -Sou en veritat, Senyor, font de tota santedat.- I com a senyal d'acabament, quan fa la reverència posterior a l'aixecament del calze. Entre aquests dos punts es desenvolupa tota l'execució de la peça, mentre el capellà continua en veu alta la litúrgia. Es produeix, per tant, una superposició de la interpretació musical amb el discurs del capellà (com devia succeir fa algunes dècades amb el Credo). De tot això se'n deriva un fet molt important: la sonada d'Alçar Déu es troba notablement condicionada, quant a durada, pel moment exacte en què s'ha d'interpretar. En el cas dels sonadors que prenen les dues referències esmentades, la seua interpretació s'ajusta al temps que transcorre entre els esmentats punts de començament i d'acabament. D’aquesta manera, si el capellà és més ràpid o més lent, fa que els sonadors tinguin més o menys temps per executar la peça.

La sonada d'Alçar Déu segueix un funcionament pràcticament idèntic al del Credo. En un primer nivell també s'identifica un cicle de repetició, que en aquest cas coincideix amb tota la sonada (alguns sonadors hi inclouen l'acaball, d'altres no). El cicle també pot aparèixer entre una i tres vegades, però sempre en execucions senceres.

En un segon nivell d'anàlisi la sonada també es divideix en una sèrie de porcions delimitades èmicament pel propi sonador, seguint el mateix procés que en el Credo. Vegeu-ho a la notació de la Figura 10. En resulta una estructura més gran, formada per dotze bocins que melòdicament també concorden amb els dos grups melòdics Fa i Do formulats anteriorment. Quasi tots els bocins tenen una part que es repeteix una o més vegades, mecànica que també es troba en la sonada anterior. És justament en aquest procés on es detecta un fet important: mentre que en el Credo les partícules repetides dins cada bocí es reiteren sempre el mateix nombre de vegades en comparar execucions diferents, en l'Alçar Déu la major part d'aquestes partícules s'executen un nombre diferent de vegades, depenent de la interpretació.

En la Figura 11 es veu més clarament el mecanisme que acabem d'explicar. El quadre recull el comportament de quatre versions de l'Alçar Déu enregistrades al mateix sonador en moments separats temporalment -la primera d'elles, formada per dos cicles-. Els números que figuren en cada casella corresponen a les vegades que s'executa cada nucli susceptible de repetició dins el seu bocí corresponent (els nuclis que en la Figura 10 estan acotats entre barres de repetició). El bocí XI, degut que té dues àrees de repetició, té dues caselles en cada cicle; la de l'esquerra representa el primer element repetible, i el de la dreta, el segon. Les caselles ombrejades indiquen aquells bocins d'extensió sempre igual. 
LES SONADES DE FLAÜTA I TAMBOR D'EIVISSA I FORMENTERA

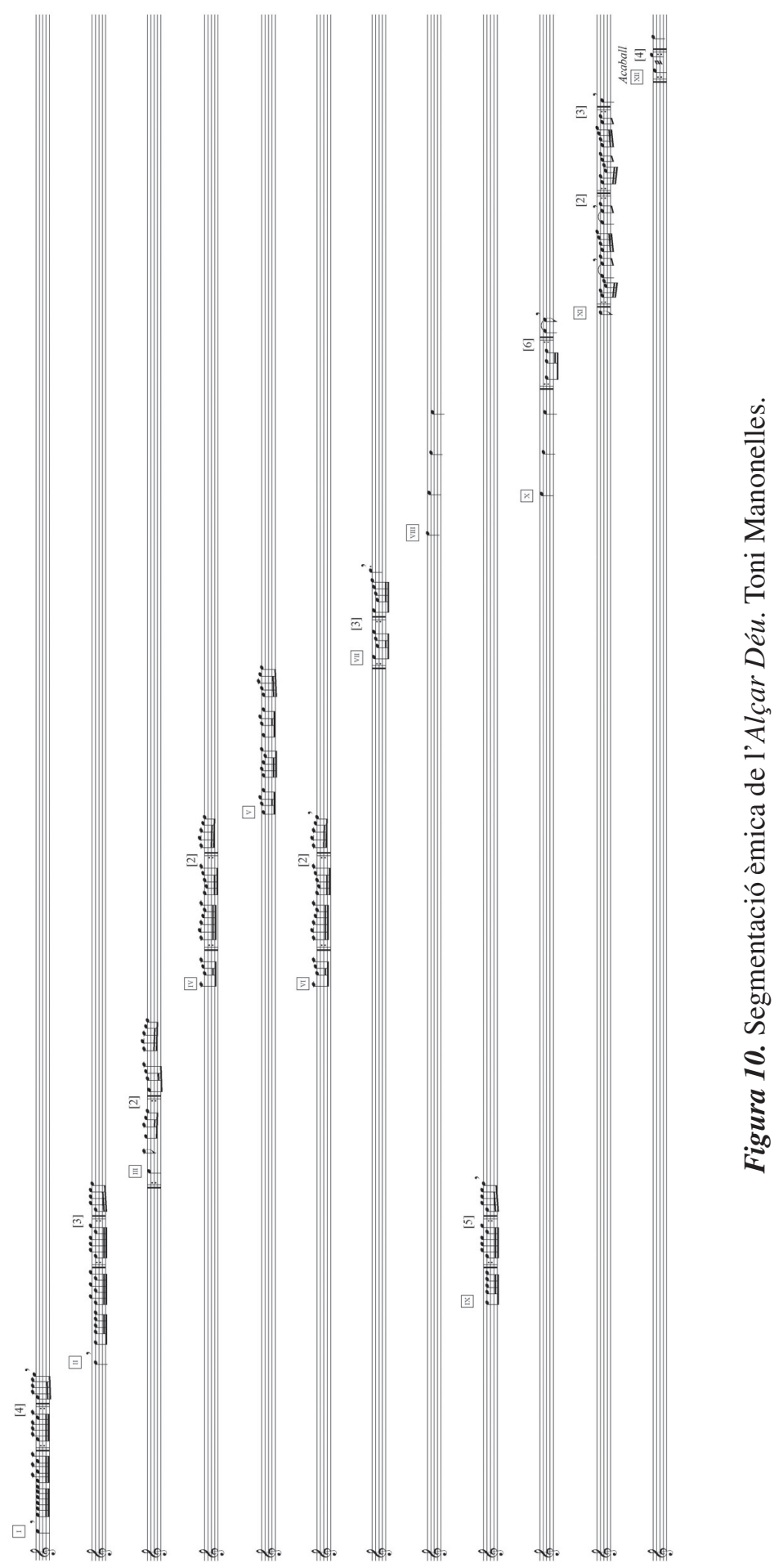

ANUARIO MUSICAL, N. ${ }^{\circ}$ 65, enero-diciembre 2010, 225-250. ISSN: 0211-3538 


\begin{tabular}{|c|c|c|c|c|c|c|c|c|c|c|c|c|}
\hline & \multicolumn{4}{|c|}{ Interpretació 1} & \multirow{2}{*}{\multicolumn{2}{|c|}{$\frac{\text { Interpretació } 2}{1 \mathrm{r} \mathrm{C}}$}} & \multirow{2}{*}{\multicolumn{2}{|c|}{$\frac{\text { Interpretació } 3}{\operatorname{1r} \mathrm{C}}$}} & \multirow{2}{*}{\multicolumn{2}{|c|}{$\frac{\text { Interpretació } 4}{1 \mathrm{r} \mathrm{C}}$}} & \multirow{2}{*}{\multicolumn{2}{|c|}{$\begin{array}{c}\text { Àmbit de } \\
\text { variació }\end{array}$}} \\
\hline Bocí & \multicolumn{2}{|c|}{ 1r C } & \multicolumn{2}{|c|}{$2 \mathrm{nC}$} & & & & & & & & \\
\hline I & \multicolumn{2}{|c|}{3} & \multicolumn{2}{|c|}{5} & \multicolumn{2}{|c|}{3} & \multicolumn{2}{|c|}{5} & \multicolumn{2}{|c|}{4} & \multicolumn{2}{|c|}{$3-5$} \\
\hline II & & & & & \multicolumn{2}{|c|}{2} & \multicolumn{2}{|c|}{4} & \multicolumn{2}{|c|}{3} & \multicolumn{2}{|c|}{$2-5$} \\
\hline III & \multicolumn{2}{|c|}{2} & \multicolumn{2}{|c|}{2} & \multicolumn{2}{|c|}{2} & \multicolumn{2}{|c|}{2} & \multicolumn{2}{|c|}{2} & \multicolumn{2}{|c|}{2} \\
\hline IV & \multicolumn{2}{|c|}{2} & & & \multicolumn{2}{|c|}{2} & \multicolumn{2}{|c|}{2} & & & \multicolumn{2}{|c|}{2} \\
\hline $\mathbf{V}$ & \multicolumn{12}{|c|}{ [No repetició] } \\
\hline VI & \multicolumn{2}{|c|}{2} & \multicolumn{2}{|c|}{2} & \multicolumn{2}{|c|}{3} & \multicolumn{2}{|c|}{2} & & & \multicolumn{2}{|c|}{$2-3$} \\
\hline VII & \multicolumn{2}{|c|}{2} & \multicolumn{2}{|c|}{2} & \multicolumn{2}{|c|}{2} & & & & & & \\
\hline VIII & & & & & & & o repe & & & & & \\
\hline IX & & & & & & & & & & & & \\
\hline $\mathbf{X}$ & & & & & & & & & & & & \\
\hline XI & 1 & 3 & 1 & 3 & 1 & 3 & 1 & 3 & 2 & 3 & $1-2$ & 3 \\
\hline XII & & & & & & & & & & & & \\
\hline
\end{tabular}

Figura 11. Variabilitat del nombre de repeticions dins els bocins. Toni Manonelles.

Ens trobem davant una sonada caracteritzada per l'elasticitat de la majoria dels bocins que la conformen. Tret del III i el IV, en què la partícula repetida s'executa sempre dues vegades, i els bocins v i VIII en què no es repeteix cap element, la resta de bocins (I, II, VI, VII, IX, X, XI i XII) són d'extensió variable. Segueixen, per tant, el principi d'elasticitat ja mencionat que es basa en la reiteració, un nombre variable de vegades, d'alguna de les partícules que el formen.

El que és més important, però, és que aquesta mecànica elàstica que es demostra en aquest esquema -i que també s'observa en analitzar les interpretacions que fan altres músics d'aquesta mateixa sonada-és reconeguda èmicament per part dels sonadors: ells mateixos reconeixen que en determinats fragments hi ha una part que es repeteix diverses vegades, i que és igualment vàlid si aquesta es repeteix més o menys cops.

D'aquest comportament elàstic que presenten gran part dels bocins, encara se'n pot dir alguna cosa més. N'observem dos models bàsics:

- Bocins de dues parts que responen a la fórmula $\boldsymbol{n} \cdot \boldsymbol{a}+\boldsymbol{a}_{\boldsymbol{t}}$

- Bocins de tres parts que s'ajusten a l'esquema $\boldsymbol{a}_{\boldsymbol{i}}+\boldsymbol{n} \cdot \boldsymbol{a}+\boldsymbol{a}_{\boldsymbol{t}}$

Els bocins de dues parts són els més simples. Estan formats per un nucli que es repeteix $\boldsymbol{n}$ vegades i que després conclou amb un altre element invariable, que només s'executa una vegada, a manera de 
nucli de terminació. En la Figura 10, els elements repetits sempre són les àrees acotades pels signes de repetició, mentre que els nuclis o elements de terminació $\left(\boldsymbol{a}_{t}\right)$ són els que apareixen just després i que conclouen el bocí. Segueixen aquest model els bocins VII i XII. El III segueix també aquest patró, encara que $\boldsymbol{n}$ té sempre el mateix valor (2). En aquest sentit, es podria considerar com una fossilització de la fórmula elàstica en un nombre fix de repeticions.

Els bocins de tres àrees són els més abundants en aquesta sonada. Estructuralment són una ampliació dels anteriors amb un element d'inici $\left(\boldsymbol{a}_{\boldsymbol{i}}\right)$ previ al nucli repetit. En la Figura 10, aquests elements inicials són els que es troben abans de les àrees acotades pels signes de repetició. Segueixen aquest model els bocins I, II, VI, IX i X. El IV es pot considerar un cas com el III; s'avé al model de bocí de tres parts, però $\boldsymbol{n}$ tendeix a adquirir un valor constant.

El bocí XI mereix una atenció especial ja que, a priori, és més difícil de classificar. No consta d'element d'inici, ja que la corxera inicial s'hagués pogut incloure dins l'àrea repetida si totes les barres de repetició s'avancessin una corxera. Però sí que té terminació, ja que el Do final, en tot cas, sempre queda fora de la darrera barra de repetició. Per tant, aparentment s'ajustaria al model de bocí de dues parts, tot i que amb la particularitat de tenir dues àrees repetides, de les quals la segona és una ornamentació de la primera. I mentre que la segona s'executa sempre tres vegades, la primera en pot aparèixer una o dues. Si es revisa, però, la Figura 11, es pot veure que només en un dels cinc cicles analitzats el primer element repetit del bocí XI s'executa dues vegades: en totes les altres, no es repeteix. Si es pren aquesta forma no repetida com a model, llavors el bocí XI encaixa perfectament com a bocí de tres parts, ja que el primer segment acotat entre barres de repetició de la Figura 10, no existiria, i tota aquesta part, per tant, es podria considerar $\boldsymbol{a}_{\boldsymbol{i}}$. El nucli repetit seria exclusivament la segona àrea acotada per les repeticions, i sempre s'executaria tres vegades (de nou, $\boldsymbol{n}$ fixada en un valor exacte), i $\boldsymbol{a}_{\boldsymbol{t}}$ o element de terminació, seguiria corresponent al Do final.

Finalment, pel que fa als bocins v i vIII, no entren dins cap dels dos grups esmentats abans, ja que no presenten repeticions.

\section{CONCLUSIONS}

El concepte d'elasticitat del qual hem parlat al llarg de l'article fa referència, inevitablement, a la possibilitat d'allargar o d'escurçar la durada de la sonada o d'algun dels seus segments. En aquest sentit, el primer que cal recordar i tenir en compte és que, tant el Credo com l'Alçar Déu, són dues sonades que estan condicionades pel desenvolupament de la litúrgia, fet que repercuteix directament en la seua durada.

Conseqüència o no d'aquest fet, s'observa que totes dues presenten mecanismes que permeten variar l'extensió total de la interpretació, cosa que permet encabir-les més còmodament en el moment de la missa que els correspon ser interpretades. Aquests mecanismes d'elasticitat apareixen a dos nivells: en la macroestructura i en la microestructura. 
A nivell macroestructural trobem que al llarg de la sonada -entesa, aquesta, com la sèrie dels elements musicals que conformen la línia melòdica de la flaüta i disposats segons l'ordre d'aparició al llarg de la peça en una sola exposició de la mateixa-, s'estableix un cicle de repetició que es pot executar entre una i tres vegades, per norma general. Aquest fet ja implica la possibilitat de modelar la durada total de l'execució.

El cicle de repetició pot ser equivalent a tota la sonada o bé reduir-se a una part central més petita: en aquest segon cas, es delimita un començament i un final que només s'executen una sola vegada, encara que el cicle es repeteixi més cops. L'estructura que en resulta s'inicia amb una fórmula d'entrada que condueix al cicle de repetició, el qual s'executa les vegades que es creuen convenients -d'una a tres-i després de la darrera repetició del cicle s'accedeix a la clàusula final o acaball, per cloure la interpretació.

Aquest és el funcionament del Credo modelitzat en la Figura 4, però el mateix model també és vàlid per a la resta de casos, tant pel Credo com per l'Alçar Déu: només cal tenir en compte que la funció d'inici previ al cicle i de clàusula final o acaball poden quedar annexionats al cicle de repetició, perdent la funció d'inici i d'acaball, però mantenint-ne la morfologia. En algunes versions això passa només amb l'inici, i en altres tant a l'inici com l'acaball (mai no ho hem trobat només amb l'acaball). Per tant, la representació del model de comportament macroestructural vàlid per a les sonades de missa estudiades és la següent:

\begin{tabular}{|llllllll|}
\hline & S & $\mathbf{O}$ & $\mathbf{N}$ & $\mathbf{A}$ & $\mathbf{D}$ & $\mathbf{A}$ & \\
\hline Inici & & & & & & & \\
\hline
\end{tabular}

I..................__ Cicle de repetició

Cicle de repetició ___....................

A nivell microestructural també existeixen mecàniques de regulació de la durada dels segments. Així, apareixen fragments formats per la repetició $\boldsymbol{n}$ vegades d'un dels elements que l'integren. El valor d' $\boldsymbol{n}$ és el d'un nombre sencer variable dins uns marges, depenent de cada cas. Aquests segments tenen un element de terminació fix i en poden tenir, també, un d'inici, de manera que es poden esquematitzar a partir de la següent expressió, exemplificada amb un bocí extret d'una de les versions de l'Alçar Déu.

$\left(a_{i}\right)+n \cdot a+a_{t}$

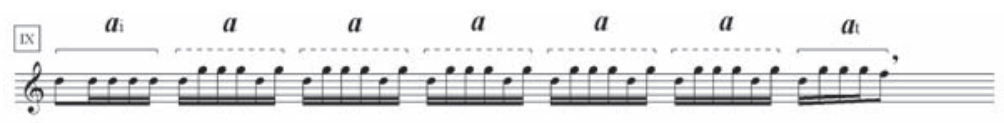

Aquesta mecànica implica que el segment en qüestió presenta extensions diferents cada vegada que s'interpreta, fet que també permet, encara que a un nivell més subtil, modificar la durada total de la sonada.

La presència d'aquest tipus de segments elàstics és molt més clara en l'Alçar Déu que en el Credo, en el qual l'únic segment d'aquesta mecànica és l'acaball. Aquest fet pot tenir una explicació: tant la sonada del Credo com la d'Alçar Déu tenen una ubicació concreta dins la missa, però mentre la primera cada vegada s'ha anat desubicant més -fins al punt que moltes vegades s'acaba sonant a la comunió-, l'Alçar Déu es manté en el seu lloc original i delimitat per senyes més concretes de la litúrgia, de manera que s'ha 
de fer encabir de la manera més ajustada possible dins aquest espai temporal. Per tant, són aquests recursos elàstics els que faciliten el millor ajustament de la sonada a l'espai temporal en què s'ha de sonar.

Aquest mateix raonament condueix a pensar que la sonada del Credo, que més antigament també tenia un espai molt més fixat i delimitat -mentre es resava l'oració del mateix nom-, segurament també es devia regir per mecanismes elàstics a nivell microestructural. Probablement, així com ha anat perdent la seua ubicació inicial i ha deixat d'estar tan condicionada temporalment, els segments s'han anat estabilitzant pel que fa a la durada, fins arribar a fossilitzar els seus elements en un nombre de repeticions sempre igual.

Pel que fa al comportament melòdic, també és important destacar les constants detectades. Les dues sonades treballades s'articulen a partir de segments amb unes característiques clares pel que fa a graus emprats i a patrons de terminació. Així, s'han establert dos models melòdics que s'han anomenat grup Fa i grup Do. En la Figura 12 es pot veure quina forma prenen en cada sonada. La nota final o grau de terminació s'ha indicat amb una línia horitzontal.

\section{Credo}
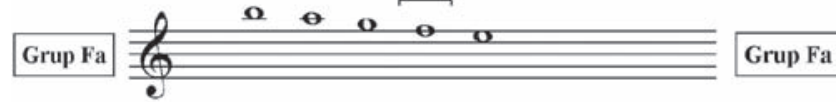

Grup Do
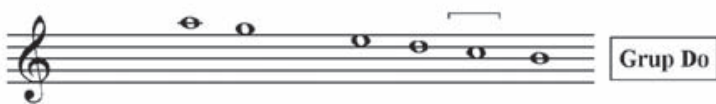

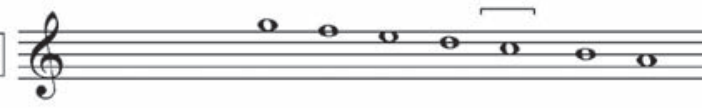

\section{Alçar Déu}

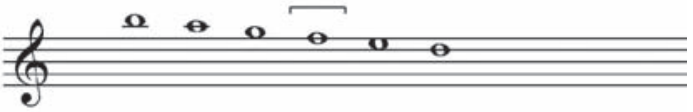
西 


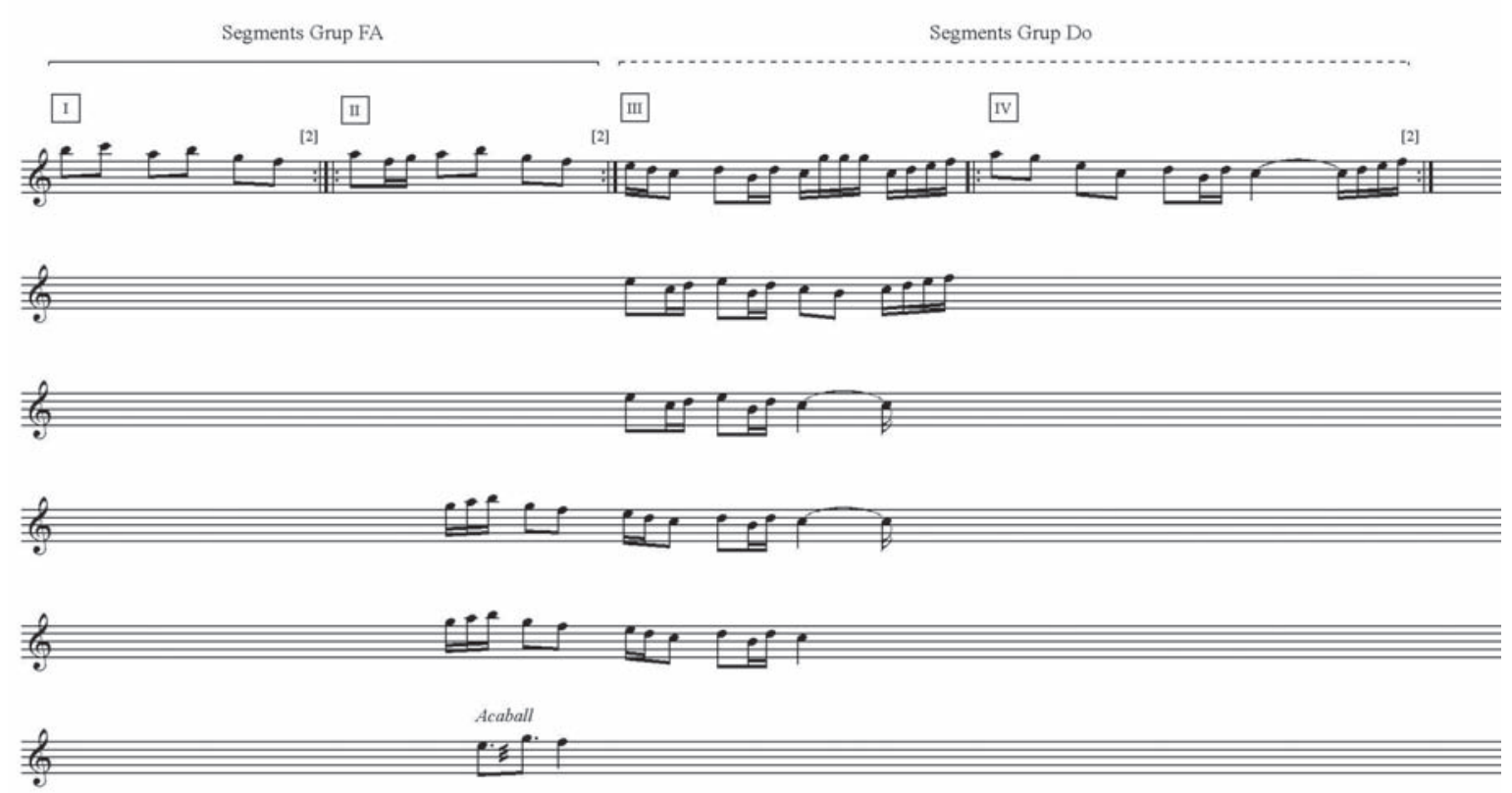

Figura 13. Reformulacions dels grups Fa i Do. Credo. Toni Escandell "Parrî́" $(* 1908 ; \dagger 1987)^{14}$.

Es pot afirmar que els mecanismes explicats al llarg d'aquest article són ben poc habituals dins els que podríem anomenar "música acadèmica". En canvi, constitueixen lògiques de funcionament no tan estranyes en altres tipus de músiques. De fet, el procediment elàstic a nivell microestructural tal com l'hem explicat aquí concorda plenament amb el que Giuriati ${ }^{15}$ va detectar en músiques de ball del centre d'Itàlia. Concretament, un saltarello de la localitat d'Amatrice. Pel que fa a les reformulacions a partir d'un esquema melòdic, el que hem trobat en aquestes dues sonades analitzades concorda en un grau molt alt amb els mecanismes que Ruwet ${ }^{16}$ va detectar en alguns exemples de monodia trobadoresca quan va formular la seua proposta analítica de 1966.

14 Notació realitzada a partir d'un enregistrament efectuat a Toni Escandell Escandell "Parrí" l'any 1980, material inèdit, fons particular.

15 GiURIaTI, Giovanni: op. cit., pp. 251-253.

16 Ruwet, Nicolas: op. cit., pp. 65-90. 


\section{ANNEX}

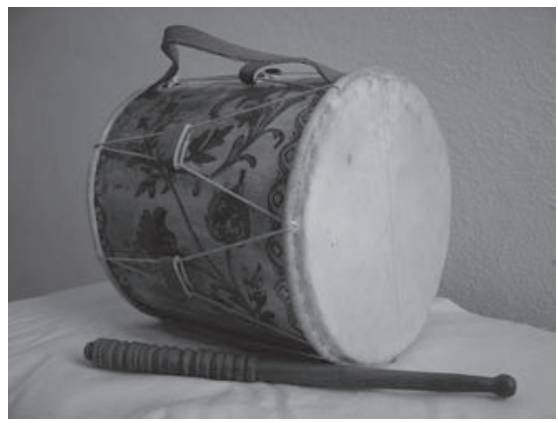

Fotografia 1. Tambor.

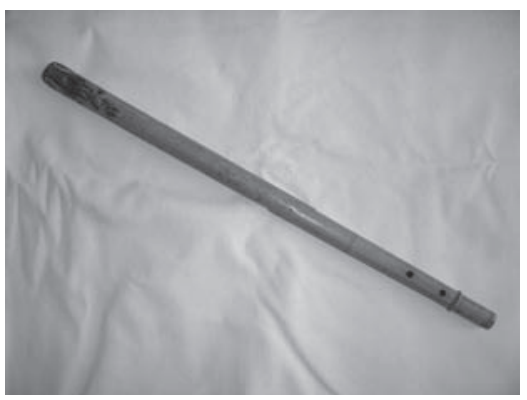

Fotografia 2. Flaüta.

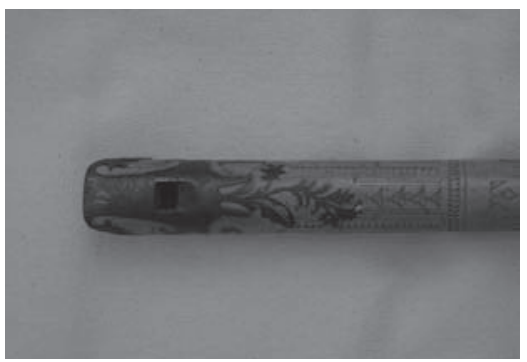

Fotografia 3. Detall de l'embocadura d'estany (estanyat). 


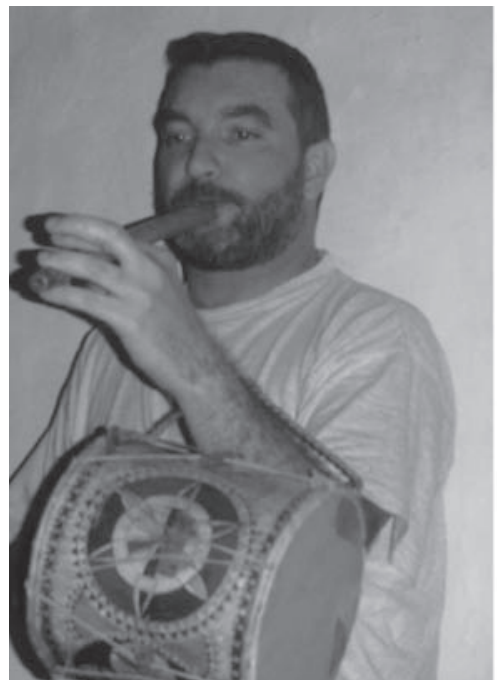

Fotografia 4. El sonador Toni Manonelles Bolle, de Sant Miquel de Balansat (Eivissa), l'interlocutor principal del treball de camp.

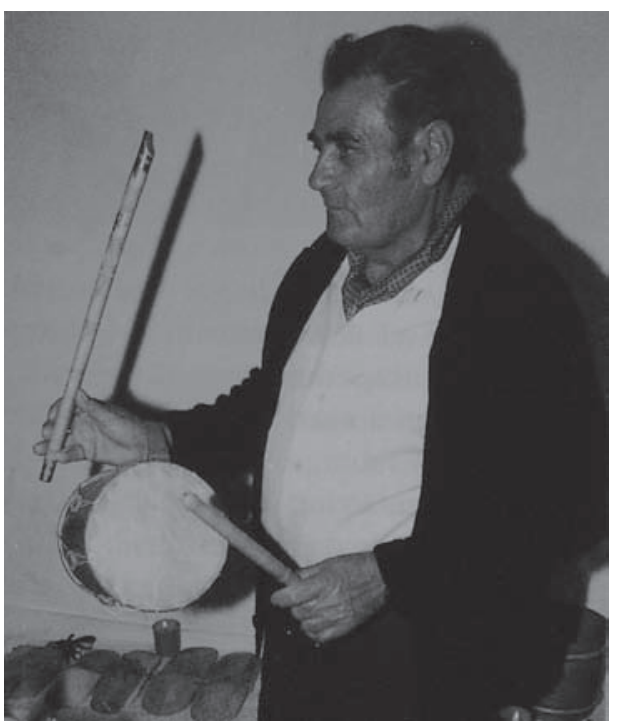

Fotografia 5. Pep Bonet Tur "Mossènyers" (*1920). Mestre de l'anterior i considerat un dels sonadors de referència per a les generacions actuals, ha estat un altre dels informadors del treball de camp.

Recibido: 25/11/2009

Aceptado: 22/02/2010 